\title{
Research on the Value and Realization Path of Developing Key Competences in Physical Education from an International Perspective*
}

\author{
Yixuan Cen \\ Research Center of Physical Education Teacher Education \\ School of Physical Education \\ Northeast Normal University \\ Changchun, China 130024
}

\begin{abstract}
Against the background of the world and the international practice in physical education, the current research explores into the values connotation and realization path of developing key competences in physical education from the perspectives of integration degree, ways of interaction, development of roles, orientation of goals, value orientation and ways to explore the potential etc. It is found that the unique nature of physical education makes it an ideal way to develop key competences. And it is of great necessity for educators to explore deeply the intrinsic value of sports and respond fully to the value pursuit of sports attributes, which is an important support for the development of key competences. The transformation and implementation of key competences in physical education can be realized by educators through infiltrating effective humanistic concern, implementing scientific structural reform and exploring learning pathways of different skills.
\end{abstract}

Keywords - international perspective; physical education; key competences; physical literacy

\section{INTRODUCTION}

Key competences are important concept in the field of educational reform theory and practice worldwide. The development of key competences promotes the reform of educational paradigm and students' ways of learning, which also reflects the gradual enrichment and broad evolution trend of the concept of abilities. Being fundamental, universal and interdisciplinary, key competences are of multifaceted features and tend to be indispensable in different fields of study, work and life. Consequently, key competences in basic education of many countries are developed both in a trans-disciplinary manner and within a single discipline. In the discipline of physical education, how to expand and give full play to the value function of this

*Fund: The research is funded by General Subject of the National Social Science Foundation in China, 2018 with the research topic of "Research on the Realization Path and Policy Coordination of the Construction of the PE Teachers' Community in Rural Areas in the New Era" (No. BLA180220) and the "13th Five-year Plan" Social Science Project of the Provincial Education Department of Jilin, China, 2019 with the research topic of "Research on the Third Space Path for the Training of PE Teachers in Rural Areas" (No. JJKH20190320SK). discipline and promote the transformation and implementation of key competences in physical education has become the concern of many international scholars and front-line educators.

\section{CORRELATION BETWEEN PHYSICAL EDUCATION AND THE DEVELOPMENT OF KEY COMPETENCES}

\section{A. Physical Education Is an Important Channel for Students to Build a Healthy Physique and Establish a Healthy Lifestyle}

As an important component of school education, physical education is closely related to health education and to the development of individuals and the whole society. With health topics being taken by many countries as national strategies, the development of public health and physique receives extensive attention. A healthy life becomes the goal in school education in many countries. In China, a healthy life has been taken as a component of key competences and become one of the six key competences of students, with the other five being cultural heritage, scientific spirit, ability to learn, undertaking of responsibility and practice and innovation. Physical education has been a key factor in the realization of a healthy way of life. The new curricular standards for physical education in basic education stipulate that physical education should abide by a guiding principle of "health first" and aim at a curriculum objective of "forming a healthy lifestyle".

It is an inevitable requirement in modern school education that health be promoted by physical education. As is shown by the third World-wide Survey of School Physical Education, the reform in physical education in the majority of the countries has put forward the idea of a healthy wellbeing and active lifestyle. Among 22 sampled European countries, key words that are the most frequently cited aims of physical education programmes include exercise and health, physical activity learning, and social and personal development [1]

It can be found in many international curricula and programs of physical education that many schools focus 
attention on students' healthy development by physical education. The curriculum of health and physical education in New Zealand emphasizes on "health" by drawing attention to students' psychological health, spiritual health, body health and family health. In United States, there are many programs related to the healthy lifestyle, such as SPARK, which is a health-oriented program to promote the development of the curriculum of physical education and the professional development of teachers, CATCH, which is a program related to physical activities and nutrition plan in the primary school, LMIS, which promotes on-campus physical activities and Planet Health, which is a transdisciplinary course related to nutrition and physical activities in the high school. In Canada, many regions carry out programs to promote the mutual and common development between physical education and health education. For example, in British Columbia, there is a program called "Action Schools", and in Alberta, "EverActive Schools" and in Saskatchewan, "Schools in Motion" and in Nova Scotia, "Active Kids, Healthy Kids and so forth [2].

The model of promotion of individual health by physical education is made up of three distinct but related strands: movement competence, active living and healthy living. Once students' movement competence is enhanced by certain strategies in physical education, students' lifelong habit of taking part in physical activities will be fostered. At the same time when students can experience the joy in physical activities, their consciousness of personal fitness and safely taking part in physical activities will be developed, thus forming a healthy and active living style. Physical education can enable students to have a clear and deep understanding of the notion of health, take part in health activities and realize the interrelation between individual health and happiness and the other people and the surrounding environment.

\section{B. Physical Education Is a Direct and Effective Method of Developing Students' Key Competences}

Physical education constitutes social and cultural activities which are characterized with body motion. Through the interaction between the body and the environment, people can foster and present their various abilities of being adapted to the environment. Different from the other disciplines which are based on ways to thinking to realize the purpose of education, physical education can be carried out in specific space and natural conditions. Thus, it can be said that physical education is relatively situational, practical and experiential. UNESCO World Conference of Ministers of Sports issues 2013 Berlin Declaration and points out that physical education is a most effective way to provide children and teenagers with skills, attitudes, values, knowledge and understanding to take lifelong participation in social activities [3]. A direct correlation can be established between physical education and the development of students' key competences. Physical education integrates students' learning of athletic abilities, cognitive exploration and emotional experience and is able to give individual learners comprehensive education and teach them useful life skills. Thus, it becomes an effective method of supporting the development of students' key competences [4]. As pointed out by Salmerón, a Spanish scholar, human body is an important factor for the interaction between human beings and the environment and physical education has a direct relation with a healthy body, a sound spirit and happiness in the society. Thus, in order to realize a benign interaction between the natural environment and the social environment, individuals' unique physical, spiritual and emotional traits have to be developed and consequently their characters, habits and attitudes are formed [5].

\section{Physical Education Curriculum Makes Potential Contribution to the Development of Every Factor of Key Competences}

The development of key competences depends on the physical education curriculum which has potential contribution to the development of every dimension of key competences. It is pointed out by some scholars that there should be adaptive changes in physical education curriculum based on the notion of the development of key competences. In the study [6] conducted by Rhona and other scholars from New Zealand defines three key competences to be developed by physical education and meanwhile explores the way in which every key competence is merged into the course and the way in which more sophisticated learning happens. Respectively, they are the ability of thinking, selfmanagement and relations with the others. Then given the environment of physical education, the way of thinking is further classified into problem solving, decision making, and ability of evaluation, creativity and introspection. Selfmanagement include subcomponents of independence, autonomy, time management, perseverance, goal setting, adaption, initiative, feedback, fair competition, selfmotivation and so forth. Relations with others are further classified into interpersonal skills, empathy, leadership skills or team spirit, inclusive nature, situation understanding, negotiation, action under motivation and so forth. Teachers need to understand the necessity in the curricular reform and actively participate in the process of developing key competences in physical education. They need to understand the key competences and all the subcomponents of every key competence and select appropriate curriculum model based on the specific teaching objective. Then the value of physical education will be shifted from attention given to the learning outcome to the attention given to the whole learning process, which will have higher requirements on the teachers.

\section{Physical Education Teaching Can Take the Role of Developing Students' Key Competences}

Given the fact that key competences combine the learning achievements from different subjects, the path of acquisition of key competences are characterized with the features of being holistic and universal. Many international modes of teaching are mature enough to have the potential to develop students' key competences, such as the teaching mode of games based on understanding, the teaching mode focusing on individual and social responsibilities and the teaching mode of sports education. These modes of teaching are of enjoyment and competitiveness and they ask for team 
work, role play and real situations, thus being compatible with teenagers' psychology and emotions during the process of acquiring skills. Teachers in physical education can discover the role of these teaching modes in developing students' key competences. They should both know what scientific understanding of key competences is and know how to put their understanding into educational practice. Once students' learning is correlated with the learning environment and other influential factors, there will be gradual changes in students' emotion, will and attitude. For example, from a sociological perspective, rules in sports competition both belong to social regulations and norms of public human activities. Physical education can guide students to follow certain rules in various sports activities and provide students with the opportunities to play a certain role and to fulfill obligations, gradually realizing individual socialization [7].

\section{E. Physical Education Is Helpful to Develop Students into Citizens Who Are of All-round Development and Adapted to the Future}

Post-2015 Education Development Agenda issued by UNESCO points out that civic education in the world should focus on the development of key competences which are the essential features "a confident and socially responsible citizen" should present [8]. High-quality physical education can offer opportunities for the acquisition of key competences, it focuses on many key factors that can promote the all-round development of people and it manifests multiple values of sports activities. For examples, physical education can promote the development of linguistic communicative abilities for the sake of conversation and group discussion while describing physical activities. It can help to develop the ability of figures because of the motion problems to be solved by numbers, operation and mathematical reasoning. It can develop the ability of learning to learn since students have to manage their own learning of sports and recognize the importance of efforts and self-improvement in creating an active and healthy lifestyle. Physical education can also develop social skills and consciousness of citizenship given the fact that learners have to cooperate and meanwhile shoulder their own and social obligations and they have to respect and abide by rules, resolve conflicts and acknowledge cultural diversity. Finally, physical education can develop cultural and artistic ability by exploring into learners' expression and artistic possibilities of body and exercises and the cultural inheritance of sports and physical activities.

\section{AdHERING TO THE PURSUIT OF VALUE OF SPORT IS AN IMPORTANT ORIENTATION IN DEVELOPING KEY COMPETENCES}

The value of physical education in developing students' key competences needs to be explored and realized by educators' deep understanding of the nature of sport and by their active response to pursuing the value of sport. In international forums, the extensive value of sport has been gradually recognized by governments and development institutions. The value of sport presents unique characteristics, the pursuit of which can extend the function of physical education and thus becomes an important orientation in developing students' key competences.

\section{A. Pursuit of a Unique Aesthetic Feature}

Sports pursue a kind of true beauty which is in line with the laws of nature and society. They will be restricted by the environment, venues, equipment, body conditions and other objective factors. Thus, the development of sport should comply with the function of human body, form and the law of bioscience. Moreover, it has to be in line with physiological and psychological characteristics of people of different ages and genders. Finally, it should conform to the authenticity of participation and abide by every law of motion.

Sports pursue a kind of technical beauty which lies in the constant advancement in science and technology. In order to improve movement ability or performance, physical education brings in many modern scientific technologies to establish scientific training systems. To some extent, it can be said that sport is a huge laboratory of modern science and technology which tests theoretical hypotheses and the invention of instrument and equipment.

Sports pursue a kind of moral beauty which is represented by a human moral principle, that is, goodness. In international sporting events, sport breaks the barrier of different cultures, ethnicities and ideas and presents a new direction of development which focuses on "peace, friendship and advancement" [9]. Even though to win is the primary objective, sport still takes goodness as the basic principle. Competition asks for noble characters such as honesty and trust which are at the same time challenged by fair competition.

Sports pursue a kind of beauty based on rationality and nature. Every type of sport shows joyous physical beauty in different forms. At the same time, the rational beauty which is contained in the inherent law of sport is a kind of abstract beauty. It is represented by a deep understanding and appreciation of sport and the connotations of movement laws in sport. It can be said that sport present a kind of heroic beauty. It's just like what is said by Lu Xun, a famous Chinese writer, "the winners definitely deserve others' respect but those athletes who are left far behind but still keep on running until they pass the finishing line are the backbone of China."

\section{B. Pursuit of Precision and the Spirit of Being Higher, Faster and Stronger}

One of the objectives in Olympic Games is to transcend the limitations of the ego and pursue the final goal of being faster, higher and stronger. The pursuit of excellence is the most fundamental spiritual motivation for sports behavior. As an internal driving force of the athletes, the objective of being higher, faster and stronger represents a condition in which the athletes can fully display their own advantages and skills [10]. Taking competitive aerobics athletes for example, the optimal state of performance is that the set of actions of the athletes are smooth, coordinated and accurate and besides 
the athletes are full of confidence and outstanding artistic expressions. The athletic skill is a kind of ability by which the sportsmen can efficiently integrate the control system of organs, the physical exercise system of muscles and bones and the system of athletic skills and knowledge with a purpose of proficiently completing a sport activity. It is acquired during the process of repetitive understanding, practice and training, with fundamental components of knowledge and cognitive factors. Given the differences of athletes with regard to the sport events they participate in, their genders and levels and given the fact that in different sport events, different dimensions of the athletic skill will make distinctive contribution to the development of the athletes, a reasonable and scientific arrangement has to be made based on specific analyses and investigations.

\section{Pursuit of an Integration of Physical Strength and Spirit}

Coubertin, the father of Olympics, states in Ode to Sport that for any athlete who wants to have a speed advantage or a height advantage, the key to success is the integration between physical strength and spirit. In spite of the fact that modern Olympic Games propose that "participation is more important than the championship", participation alone cannot represent human strength and wisdom. The foundation of the success in sports competition lies in the objective factors of actual strength and wisdom. The use of wisdom, stable psychology and proper display of the athletic skill all take actual strength as the foundation and on the other hand, the normal display of strength is guaranteed by the accumulation of wisdom.

Sport is an embodiment of the spirit from the competition between human beings and the natural world and even between human being and themselves. Every movement, like running, jumping, tossing and throwing, condenses the strength and wisdom of mankind. Without the competition of strength, there will be no sports activities at all and neither competition. In athletic competition, strength is mainly represented by two dimensions. One is the competition of human natural power which is based on the competitors' physique and physical fitness and reflected by speed, endurance, bounce, sensitivity and accuracy. The other is the competition of wisdom which is symbolized by prudence, decisiveness, resolution and calmness.

\section{Pursuit of Cooperative Spirit and an Excited State Effect}

In the process of sport development, cooperative spirit is represented by a conflicting and blending process of all the participants' common ideals, beliefs, value pursuit, ethics and volitional qualities. The cooperative mechanism aggregates and organizes group wisdom and the effective application of the cooperative mechanism can help to avoid the group disadvantages, strengthen the group discipline and the internal cohesion and finally improve the team's competitiveness.

In an excited state, the athletes' strength is stronger than the normal condition because of the interaction between certain motivation and the surrounding environment. An environmentally excited effect will be triggered for the athletes in the competition environment. It presents a manner of indirect interaction, assisting the group to cooperate with each other even in an environment with loose organization. Through leaving pheromones which can be recognized by the group in the shared environment, a consensus will be developed, which will encourage the follow-up participants to take effective actions in a fast-changing and intense environment of sports games. Thus, it can be said that the environment-based excited state effect provides an important cooperative mechanism among participants in the same group.

\section{The Path of DeVEloping Key COMPETENCES IN PHYSICAL EDUCATION}

\section{A. There Should Be Humanistic Care in Physical Education}

The value pursuit in physical education shouldn't be neglected in developing students' key competences and meanwhile the constant development of physical education can constitute an important condition for the development of students' key competences. During the teaching process, PE teachers' humanistic concern to students can help them to build characters and abilities which are essential for lifelong development of the learners and the development of the whole society. The breadth and depth of humanistic care will influence the effect of physical education.

Firstly, teachers should respect students' dominant role in physical activities. Teachers should understand that there are different forms of students' dominant role. Thus, it is necessary to display students' all possible roles in participation. Humans in physical activities represent different forms of existence, including material existence, spiritual existence and cultural existence, each of which is of unique features. In addition, teachers should recognize students' different development conditions and their particularities. Finally, teachers' humanistic concern for students should focus on whether students' requirement of development and improvement is met in sports activities rather than on the development forced by external force.

Secondly, teachers should acknowledge students' value in physical activities. On one hand, students should be helped to establish correct values and be encouraged to develop a value orientation of acquiring key competences. On the other hand, educators in physical education should fully recognize and develop the individual and group value, combining the social value and the individual value of mankind.

Thirdly, physical education should motivate students to pursue truth, goodness and beauty. Students should understand the truth, goodness and beauty contained in and the humanistic spirit delivered in physical activities. Teachers should create game and motion scenarios which are closely related to the teaching practice to inspire students desire for knowledge, performance and achievement. Teachers have to put into practice the development-oriented principle by creating a situation in which students' motivation, confidence and athletic skills are improved. Then in a situation in which there are social relationships among schools, families and the society, both the body and the spirit of the students will be in coordinated development. 


\section{B. There Should Be Scientific Structural Reform in Physical Education}

UNESCO points out that it is a foundation in physical education to develop students' physical competences. The development of students' key competences is not a plan but an outcome of institutional physical education. With regard to the students' acquisition of key competences, there should be a scientific structural reform in physical education, guiding a coordinated process of advancement.

Firstly, there should be a time structure in physical education since with proper opportunities, which will be much easier for learners from different age groups and in different life stage to attain established results. In the primary school, pupils are in a sensitive period of physical development and also a key period when their sports values, sports abilities and qualities are formed. To improve students' key competences of physical education constitutes a key feature in the physical education curriculum in primary and high school education. High-quality physical education can help children and adolescents to acquire physical competences, which will run through the whole process of basic education from the early educational period to the period of high school.

Secondly, there should be a structured goal in physical education. Siedentop, an American sports educator, believes that the goal in physical education is to foster students' abilities of enjoying physical activities, including their athletic skills, knowledge and social behaviors. He holds that there should be a structured goal in physical education. Besides, the goal should be made compatible with realistic situations, thus becoming an "achievable goal" to be realized by the teaching practice. He also puts forward specific strategies for the realization of the "course goal" in each unit and the "teaching objective" in every class hour [11].

The third reform is related to the structured reform in the trans-disciplinary curricular content in physical education. The content of physical education which is based on the development of students' key competences should be designed in a trans-disciplinary manner and physical education should be studied from a general scientific and educational perspective. Besides, knowledge of other disciplines should be brought into the process of physical education and meanwhile be given explanation from the perspective of physical education. The structured reform in the design of the trans-disciplinary curriculum should not only focus on the cross-combination between physical education and the other subjects, like art, life science, social science and so forth [12], but also organize different interdisciplinary groups, such as the group of humanistic sociology of physical education, athletic skills development group and so on and so forth.

Fourthly, there should be structured reform in PE teacher's teaching abilities. Under the framework of key competences, PE teachers face many challenges on their teaching abilities and teaching skills. Thus, teachers should improve their capabilities of being adapted to the new mode of teaching and responding to it in an effective manner. Besides, teachers should improve their comprehensive abilities in many aspects, such as their ability of transforming knowledge, of teaching students to be capable, of applying the new mode of teaching and of expanding expectation of students' learning achievements. With a purpose of improving these abilities of teachers, there should be a reform in teachers' knowledge structure and a change from the single knowledge structure to the group knowledge structure and also a change from abstract knowledge to theoretical and practical knowledge.

\section{Physical Education Should Explore Paths of Learning Various Skills}

UNESCO points out students' key competences in physical education can be developed through the improvement of students' cognitive and non-cognitive skills In order to study those skills, teachers have to find more learning paths for students. Inevitably, there will not be only one learning path for all students given the fact that goals, methods, surrounding environment are different.

Firstly, quality physical education provides students with a learning path of acquiring key competences. The development of key competences asks for students' ability of communicating and interacting with themselves, the others and the society by the help of certain tools and means. This special requirement seems to be identical with that in physical education. It is stated by UNESCO that physical education can be a learning path for students to acquire 21st century skills. The contribution of quality physical education to the 21 st Century education lies in the four aspects. The first is to provide students with education of life skills and to develop their habit of lifelong participation in physical activities. The second aspect is related to developing students into responsible and active citizens. The third aspect is inseparable from teaching students' essential knowledge for academic achievement and building their confidence. The last contribution is to develop students' skills and values.

Secondly, quality physical education supplies the learning path of acquiring key skills. Any type of sports activity needs key skills which do not come from the simple accumulation of specific professionalized knowledge and skills but depend on quality physical education. Teachers should take different types of sports activities into consideration and design specific situations to support individual learners' effective participation and interaction. Superb athletic skills can be acquired by the comprehensive application of individuals' cognitive skills, skills of practice and creativity and also a full motivation of learners' attitude, value and other psychological factors. Gradually, students proficiency in controlling their limbs in motion will be improved.

Thirdly, the ability of "coordination and control" in quality physical education is the fundamental condition for the interaction among different skills. UNESCO report on quality physical education points out that individuals with fine physical qualities have strong confidence and are able to deal with the fast-changing environment because of the ability of coordination and control [13]. Those individuals share many things in common. For example, they can have 
good relationship with others, being cautious and empathetic. They acquire different athletic skills and like to explore and take part in new physical activities. They understand the significance of knowing the systematization, rules, and strategies for implementation and evaluation and meanwhile they can make flexible use of concepts, principles and strategies which are closely related to sports, performance and healthy lifestyles. Individuals with fine physical qualities will take lifelong participation in physical activities as an indispensable part in their lives and physical education constitutes the foundation for citizens' continuous participation in physical activities.

\section{CONCLUSION}

In conclusion, physical education has great potential in developing key competences of students, which is reflected in the analysis and transformation of key competences elements in physical education curriculum, the selection of teaching modes and the exploration and application of its potential roles, the infiltration and cultivation of cognitive and non-cognitive skills and so on. The development of students' key competences in physical education presents the characteristics of integration, directness, effectiveness, permeability, long lasting, experiencing and situatedness. And the uniqueness and heterogeneity of physical education determines it is a perfect combination with the development of key competences.

\section{REFERENCES}

[1] UNESCO. World-wide Survey of School Physical Education [R]. Paris, France, 2014.

[2] Hickson, C., Robinson, D. B., Berg, S., \& Hall, N. Active in the north: School and Community Physical Activity Programming in Canada [J]. International Journal of Physical Education, 2012.

[3] UNESCO. Declaration of Berlin. MINEPS V, Berlin, Germany, May 28-30, 2013.

[4] TERESA LLEIXÀ. The Contribution of Physical Education to the Acquisition of Key Competences: Establishing Dimensions [EB/OL]. (2016-02-09)[2016-12-11]. http://efdeportes.com/efd213/physicaleducation-to-key-competences.htm.

[5] TERESA LLEIXÀ. The Contribution of Physical Education to the Acquisition of Key Competences: Establishing Dimensions [EB/OL]. (2016-02-09)[2016-12-11]. http://efdeportes.com/efd213/physicaleducation-to-key-competences.htm.

[6] GILlESPIE L, PENNEY D, POPE C. Untapped Potential? Key Competency Learning and Physical Education [J]. Teachers \& Curriculum, 2013, 13(3):11-18.

[7] Tianwen, Zhang, Bingquan, Luo. On the Rule Education and Its Values in Physical Education [J]. Sports Culture Guide, 2013(9).

[8] MCLENNAN N, THOMPSON J. Quality Physical Education: Guidelines for Policy Makers [R]. UNESCO, 2015

[9] Douyan, Xiong. The Enlightenment of Ode to Sport [J]. PE and Science, 1988(4):2-6.

[10] Ni, Zhao. Symbol and Memory: The Connotation, Characteristics and Value of Women's Volleyball Spirit [J]. Sports Culture Guide, 2017(8).

[11] DarylSiedentopWrited. Developing Teaching Skills in Physical Education [M]. 2nd ed. Mayfield Publishing Company, 1983.

[12] Ling, Yang, De, Zhu. Cultural Representation beyond Skills-The Pursuit of Cultural Characters in Physical Education [J]. Educational Research, 2014(10): 106-111.
[13] MCLENNAN N, THOMPSON J. Quality Physical Education: Guidelines for Policy Makers [R]. UNESCO, 2015. 